DOI: https://doi.org/10.24867/10GI06Nicic

\title{
ANALIZA FINANSIJSKIH PERFORMANSI I IZLOŽENOSTI RIZICIMA U FUNKCIJI DONOŠENJA ODLUKE O KREDITIRANJU
}

\section{ANALYSIS OF FINANCIAL PERFORMANCES AND RISK EXPOSURE IN THE FUNCTION OF MAKING CREDIT DECISIONS}

\author{
Milica Ničić, Fakultet tehničkih nauka, Novi Sad
}

\section{Oblast - INDUSTRIJSKO INŽENJERSTVO I MENADŽMENT}

Kratak sadržaj - Proces odobravanja kredita se bazira na primeni složene procedure, gde je više bankarskih sektora uključeno $u$ analizu $i$ donošenje odluke o kreditiranju klijenta. U okviru kreditne analize detaljno se obrađuje finansijski $i$ tržišni aspekt poslovanja preduzeća. Finansijska analiza značajno utiče na donošenje pozitivne odluke o odobravanju kredita, ali se u kombinaciji sa drugim analizama donosi konačna odluka o odobravanju kredita. Pored toga, kreditni analitičar posebnu pažnju usmerava na način identifikacije rizika $i$ izloženosti rizicima preduzeća u svom poslovanju.

Ključne reči: Finansijske performanse, finansijska analiza, rizici

\begin{abstract}
The loan approval process is based on the application of a complex procedure, where several banking sectors are involved in the analysis and decision-making on lending to the client. Within the credit analysis, the financial and market aspect of the company's business is processed in detail. Financial analysis significantly influences a positive decision to grant a loan, but in combination with other analysis, a final decision on loan approval is made. In addition, the credit analist pays special attention to the way risks are identified as well as level of risk exposure companies are subjected to in theis business.
\end{abstract}

Keywords: Financial perfomances, financial analysis, risks

\section{UVOD}

Prilikom podnošenja zahteva za kredit u banci, preduzeće treba da priloži svu potrebnu dokumentaciju i bude na raspolaganju banci za sve neophodne informacije. Primenom složene bankarske procedure analiziraju se svi relevantni aspekti poslovanja preduzeća koji su od značaja za odnošenje odluke o odobravanju kredita.

Analizira se tržište i industrija u kojoj preduzeće posluje, vrši finansijska analiza kroz izračunavanje najvažnijih racio pokazatelja $\mathrm{u}$ prethodnom trogodišnjem periodu. Kreditni analitičari specificiraju rizike kojima je preduzeće izloženo u svom poslovanju, a sve u funkciji donošenja odluke o kreditiraju preduzeća.

\section{NAPOMENA:}

Ovaj rad proistekao je iz master rada čiji mentor je bila prof. dr Jelena Demko Rihter.

\section{POJAM I ZNAČAJ FINANSIJSKOG IZVEŠTAVANJA}

Finansijsko izveštavanje o stanju, uspehu i tokovima sredstava preduzeća i drugih pravnih lica je upravljačka nadležnost i odgovornost menadžmenta. Ono je u stručnoj odnosno profesionalnoj nadležnosti finansijskog računovodstva i glavnog računovođe preduzeća i drugih organizacija. Kad su finansijski izveštaji objavljeni oni su predmet slobodne interpretacije od strane svakog korisnika, odnosno njegovog analitičara [1]. Osnovni cilj finansijskog izveštavanja jeste sagledavanje realne i objektivne finansijske situacije preduzeća. Da bi se taj cilj ostvario, neophodno je izvršiti finansijsku analizu, koja na osnovu sagledavanja sadašnjih i prethodnih ostvarenja predstavlja osnovu za predviđanje budućeg finansijskog stanja [2].

\subsection{Korisnici finansijskih izveštaja}

Najznačajniji korisnici finansijskih izveštaja su investitori i kreditori, bilo da se radi o sadašnjim ili potencijalnim, kao i menadžment preduzeća. Međutim može se govoriti o čitavom nizu korisnika koji se najčešće dele u dve grupe: eksterni (npr. akcionari, poslovni partneri, konkurencija, banke $\mathrm{i}$ ostale finansijske institucije, državni organi, privredne komore itd.,) i interni korisnici (npr. nadzorni odbor, menadžment, zaposleni, sindikat i drugi). Svi navedeni korisnici zainteresovani su za kvalitet finansijskih izveštaja koji je potrebno razmatrati u kontekstu kvaliteta računovodstvenih informacija [3].

\subsection{Pojam finansijskih izveštaja}

Finansijski izveštaji saopštavaju finansijsku poziciju preduzeća na tačno određeni dan, ali su i pokazatelji poslovanja preduzeća u određenom vremenskom periodu. $\mathrm{Na}$ osnovu informacija sadržanih u finansijskim izveštajima mogu se sagledati i oceniti ostvarenja preduzeća iz prethodnog perioda i na osnovu toga predvideti ostvarenja u budućem periodu, što ujedno predstavlja informacionu podršku menadžerima za donošenje poslovnih odluka i za planske aktivnosti, što se odražava na rezultat poslovanja preduzeća u kraćem i dužem vremenskom periodu. Finansijski izveštaji se uobičajeno sastavljaju uz pretpostavku da preduzeće vremenski neograničeno posluje i da će nastaviti da posluje u doglednoj budućnosti.

\subsection{Namena finansijskih izveštaja}

Namena finansijskih izveštaja je da svim zainteresovanim pruže informacije o imovinskom i finansijskom stanju preduzeća, kao i o promeni stanja. Oni imaju i određena ograničenja, budući da uglavnom ne daju sliku o imovinskom stanju u budućnosti i ne sadrže nefinansijske 
informacije. Oni takođe pokazuju rezultate rada menadžmenta ili odgovornosti menadžmenta za poverene resurse i služe kao osnova za donošenje odluka u vezi s ulaganjima u preduzeće. Sastavni delovi finansijskih izveštaja su u uzajamnoj vezi jer odražavaju različite aspekte istih transakcija.

Nijedan od njih ne služi samo jednoj svrsi i ne pruža potpunu sliku o uspešnosti ako se ne koristi bilansom stanja i izveštajem o promenama finansijskog položaja. [4].

\subsection{Značaj i uloga revizije i međunarodnih standarda finansijskog izveštavanja (MSFI)}

Da bi se izbegle pogrešne poslovne odluke, upravljanje mora biti zasnovano na realnim i objektivnim, tj. istinitim i fer informacijama. Isticanjem realnosti i objektivnosti informacija u razmatranje se uvodi problematika revizije. Povezano sa tim, nameće se pitanje koja je zapravo uloga revizije u tržišnoj ekonomiji.

Revizija, pre svega, štiti interes vlasnika kapitala, zatim pomaže u pribavljanju dodatnog kapitala i obezbeđuje realne i objektivne informacije za upravljanje. Zbog toga se često ističe $\mathrm{i}$ to da je revizija vrlo značajna pretpostavka preduzetništva [5].

MSFI imaju značajnu ulogu u ujednačavanju finansijskog izveštavanja na globalnom nivou. Glavni cilj MSFI jeste da se poveća razumljivost i uporedivost finansijskih izveštaja radi sagledavanja što realnijeg finansijskog položaja privrednih entiteta. MSFI su uvedeni da bi se postigla transparentnost i jednoobraznost finansijskih izveštaja bilo kog ekonomskog subjekta, bez obzira na delatnost kojom se bavi i zemlju u kojoj posluje. Ovi standardi čine koncepte koji se koriste za konvertovanje računovodstvenih evidencija $u$ pouzdane računovodstvene izveštaje, tj. unificirana pravila za eksterno izveštavanje [6].

\subsection{Vrste finansijskih izveštaja}

Informacije koje se pružaju korisnicima o finansijskom položaju preduzeća I uspešnosti poslovanja su sadržane u redovnim godišnjim finansijskim izveštajima, koji mogu biti:

- Bilans stanja,

- Bilans uspeha.

- Izveštaj o ostalom rezultatu.

- Izveštaj o promenama na kapitalu.

- Izveštaj o tokovima gotovine.

- Napomene uz finansijske izveštaje.

U zavisnosti od veličine preduzeća, se razlikuju ovi izveštaji.

\section{POJAM I ULOGA ANALIZE FINANSIJSKIH IZVEŠTAJA}

Analiza finansijskih izveštaja se predstavlja kao osnova za procenu perspektivi, predstavlja spoj prošlosti i sadašnjosti radi donošenja boljih odluka u budućnosti. Ona daje odgovor na pitanje kako je preduzeće poslovalo u prethodnom vremenskom periodu i kako da poboljša rezultate $u$ narednom razdoblju. Odnosi se na podvrgavanje finansijskih izveštaja analitičkom ispitivanju kroz upotrebu odgovarajućih metoda $\mathrm{i}$ instrumenata sa ciljem ocene finansijske situacije preduzeća. Za opšte analize finansijskih izveštaja se podrazumevaju vertikalna, horizontalna i grafička analiza.

\subsection{Uloga i značaj racio analize}

Odnos jedne bilansne pozicije prema drugoj, izražen u prostoj matematičkoj formuli, naziva se racio. Značaj supstitucije apsolutnih vrednosti racio-brojevima proističe iz potrebe da se utvrde i izmere one uzorčne veze između bilansnih pozicija koje osvetljavaju neki od finansijski relevantnih aspekata poslovne aktivnosti preduzeća [10].

$\mathrm{U}$ racio odnos stavljaju se bilansne veličine koje su međusobno povezane ili uslovljene. Racio pokazatelji su nosioci informacija koje su potrebne za odlučivanje i upravljanje preduzećem. Pokazatelji se izračunavaju i upotrebljavaju zavisno od interesa donosioca poslovnih odluka. Tako su vlasnici kapitala zainteresovani za dugoročnu profitabilnost i sigurnost. Menadžment preduzeća je zainteresovan za sve pokazatelje poslovanja, jer se brine o likvidnosti, kratkoročnoj i dugoročnoj finansijskoj stabilnosti i profitabilnosti.

\section{Pokazatelji likvidnosti}

Likvidnost preduzeća je njegova sposobnost da u roku isplaćuje svoje dospele obaveze. Likvidnost preduzeća proističe iz odnosa likvidne imovine i kratkoročnih obaveza na bilansni dan. Likvidnom imovinom se smatra obrtna imovina. Ocena povoljnosti bilo kog od ovih odnosa zavisi ne samo od visine racia koji taj odnos izražava, već i od strukture i ročnosti imovine o kojoj je reč i od ročnosti kratkoročnih obaveza na bilansni dan. Najznačajniji pokazatelji likvidnosti su:

- Koeficijent trenutne likvidnosti

- Koeficijent ubrzane likvidnosti

- Koeficijent tekuće likvidnosti

\section{Pokazatelji zaduženosti}

Zaduženost se prikazuje preko strukture pasive bilansa stanja posmatrane sa stanovišta vlasnika. Pokazatelji zaduženosti prikazuju koliko je preduzeće zaduženo i rizičnost njegovog zaduživanja. Neki od pokazatelja zaduženosti su:

- Finansijski leveridž

- Koeficijent sopstvenog finansiranja

- Faktor zaduženosti

- Indikator samostalnosti finansiranja

- Solventnost

\section{Pokazatelji aktivnosti}

Pokazatelji aktivnosti se dobijaju na osnovu podataka iz bilansa stanja i bilansa uspeha i izražavaju broj dana zadržavanja poslovnih sredstava u konkretnom obliku. Najznačajniji pokazatelji aktivnosti su:

- Pokazatelji obrta ukupne poslovne imovine

- Pokazatelji obrta obrtnih sredstava (zaliha, robe itd.)

- Pokazatelji obrta potraživanja od kupaca

- Pokazatelji obrta obaveza prema dobavljačima

\section{Pokazatelji profitabilnosti}

Dva nabitnija pokazatelja profitabilnosti su bruto marža profita i neto marža profita.

Bruto marža profita je pokazatelj kojim se meri adekvatnost cenovne strategije u smislu odnosa cena i troškova preduzeća. Pokazuje koji deo prihoda od prodaje preduzeće zadržava u obliku dobiti pre oporezivanja Bruto marža se u stranoj literaturi naziva i EBIT maržom. 
Neto marža profita je važan pokazatelj koji najpreciznije pokazuje konačan rezultat realizovanih poslovnih aktivnosti. Iz njega je vidljivo koji deo prihoda ostaje preduzeću u vidu dobiti kojim može slobodno raspolagati i koji predstavlja osnovu za razvoj i unapređenje poslovanja [11].

\section{POJAM RIZIKA I IZLOŽENOST RIZICIMA U POSLOVANJU}

Postoji mnoštvo definicija rizika, a u najopštijem smislu može se reći da se pojam rizika odnosi na manju ili veću neizvesnost u pogledu očekivanog ishoda poslovne aktivnosti.

Suština te neizvesnosti proističe iz nedovoljnosti i nepouzdanosti informacija na bazi kojih se donose poslovne odluke. Kod rizika postoji određena verovatnoća nastajanja, dok je kod neizvesnosti nemoguće odrediti verovatnoću nastajanja.

\subsection{Rizici kojima je preduzeće izloženo u svom poslovanju}

U procesu odobravanja kredita i kasnije otplate kredita, banka je izložena jedino kreditnom riziku, tj. riziku da li će klijent uspeti da vrati dug sa pripisanom kamatom. Tokom tog procesa i preduzeće je izloženo raznim rizicima, koji mogu uticati na to da li će moći da dobije kredit od banke $\mathrm{i}$ da ga vrati u budućnosti. Rizici kojima je izloženo preduzeće u svom poslovanju, a ispoljavanje tih rizika može ugroziti otplatu kredita u banci će biti objašnjeni u nastavku.

Strateški rizik - odnosi se na odluke direktora preduzeća koje on donosi u vezi sa ciljevima preduzeća. Ovaj rizik se javlja ukoliko se ne ostvaruju postavljeni ciljevi preduzeća. Strateški rizik može da bude kratkotrajan i dugotrajan. Ukoliko strateški rizik utiče na svakodnevne aktivnosti poslovanja preduzeća onda je to kratkotrajan rizik, a ukoliko se odnosi na strateške odluke koje se donose u budućnosti, onda je to dugotrajan strateški rizik.

Operativni rizik - je rizik ljudskog faktora. Javlja se usled sukoba internih interesa u okviru jednog preduzeća. Ovaj rizik se može javiti kao posledica lošeg rukovodstva menadžmenta. Kvalitet menadžmenta je veoma važan, a uglavnom i ključan faktor za dugoročnu stabilnost preduzeća. Potrebno je stalno usklađivanje unutrašnjih resursa preduzeća i adekvatno pozicioniranje na tržištima.

Rizik zemlje - nastaje usled ekonomskih, socijalnih, pravnih ili političkih poremećaja koji su se desili na teritoriji zemlje u kojoj preduzeće posluje. Ovi poremećaji se najčešće ne mogu lako predvideti i preduzeće uglavnom ne uspeva da izbegne ovaj rizik ukoliko nastane. U rizik zemlje spada i nestabilnost jedne zemlje u pogledu visoke nezaposlenosti, inflacije, deficita budžeta itd.

Tržišni rizik - predstavlja rizik od promene tržišnih cena i odnosa razmene, koji dovode do sniženja vrednosti pojedine finansijske imovine i njihovih portfolia. Neki od najvažnijih tržišnih rizika su: valutni rizik, kamatni rizik i kreditni rizik.
Valutni rizik - nastaje zbog promene deviznog kursa jedne valute u odnosu na drugu valutu. Preduzeće je izloženo ovom riziku ukoliko posluje van granica svoje države, tj na inostranom tržištu. Ovaj rizik je izuzetno nepredvidiv i preduzeće je izloženo deviznom riziku ukoliko promena deviznog kursa ima negativan uticaj na vrednost imovine, investicija itd.

Kamatni rizik - nastaje ukoliko menjanje kamatne stope ima štetan efekat na poslovanje preduzeća. Kamati rizik se može javiti u dva slučaja, i to, ukoliko se preduzeće želi zadužiti, a kamatna stopa se poveća, ili ukoliko preduzeće želi investirati svoja novčana sredstva, a kamatna stopa se smanji. Kamatni rizik se može izbeći jedino ukoliko preduzeće finansira svoje poslovanje isključivo iz sopstvenih sredstava.

Kreditni rizik - se javlja ukoliko preduzeće nije u stanju da naplati svoja potraživanja zbog nelikvidnih dužnika. Kreditni rizik nastaje kada preduzeće pozajmljuje, investira ili daje kredit i odnosi se na povraćaj pozajmljenog novca ili isplate od prodate robe ili usluga. Ukoliko klijent ne želi ili ne može da plati preduzeću svoje obaveze povećava se kreditni rizik. Ovaj rizik utiče na likvidnost preduzeća, što je veći kreditni rizik, javlja se i veći rizik likvidnosti. Na kreditni rizik preduzeće može da utiče tako što će različitim instrumentima podsticati i ubrzavati naplatu potraživanja od svojih kupaca.

\section{METODOLOGIJA ZA ODOBRAVANJE KREDITA}

Procedura odobravanja kredita u bankama je veoma složen proces u koji je uključeno više bankarskih sektora, kako bi se donela odluka o kreditiranju preduzeća. Procedura počinje od apliciranja klijenta za kredit do samog odobravanja i kasnije praćenja otplate kredita. Metodologija koja se koristi u procesu odobravanja kredita je poslovna tajna svake banke, ali je za potrebe master rada prikupljeno više metodologija i napravljena jedna opšta.

\subsection{Istorijat i opis poslovanja preduzeća Laki komerc}

Za primer analize, izabrano je preduzeće Laki komerc doo iz Banatskog Novog Sela koje je osnovano 2004. Ovo preduzeće pripada prerađivačkoj industriji, ali se bavi i trgovinom na veliko mesom i proizvodima od mesa na teritoriji Srbije. Laki komerc poseduje sve dozvole za klanje pilića. Pripada kategoriji srednjeg preduzeća i trenutno ima 119 zaposlenih. Nema povezanih lica i nije članica ni jedne druge grupe.

\subsection{Analiza konkurencije}

Upoređeni su najvažniji finansijski rezultati 3 glavna konkurenta Laki komerc-a, a to su Matijević, Pile prom i Big bull. Uporednom analizom, uočilo se da Matijević, kao veće preduzeće od ostalih ima i najveću bruto i neto dobit, ali Laki komerc ima veću neto dobit u odnosu na druga dva konkurenta. U svim pokazateljima aktivnosti, Laki komerc ima najveći koeficijent obrta potraživanja od kupaca. 


\subsection{Analiza operativnih prihoda kompanije}

Analizom operativnih prihoda, se došlo do zaključka da je specifičnost u klaničnoj industriji to što se sa klijentima postiže dogovor oko cene živih pilića i pilećeg mesa koje je zamrznuto na godišnjem nivou, pa fluktuacije na tržištu tokom godine nemaju veliki uticaj. Ono što utiče na prihode od prodaje jeste promena obima celog tržišta.

\subsection{Racio analiza kompanije}

Racio analiza je rađena za prethodne 3 godine, gde su računati osnovni racio pokazatelji. Zbog velikog učešća zaliha u ukupnim obrtnim sredstvima preduzeće ima problem sa likvidnošću - opštom i rigoroznom. Racio pokazatelji zaduženosti su pokazali da Laki komerc nema rizična ulaganja $i$ da je solventno u svim godinama posmatranja. U u svim godinama se ostvaruje dobit, ali su bruto i neto profitna marža na niskom nivou.

\subsection{Zaključak na osnovu finansijske analize}

$\mathrm{Na}$ osnovu sprovedene finansijske analize kompanije Laki komerc, došlo se do zaključka, da bi na osnovu dobijenih rezultata, banka mogla odobriti kratkoročni revolving kredit u iznosu od 23.600.000 RSD, ili 200.000€ za obrtna sredstva.

\subsection{Metodologija za analizu rizika}

Drugi deo istraživačkog rada odnosi se na metogologiju za analizu rizika i njihovu identifikaciju. Nizak nivo rizika je zabeležen za tehnološku inovaciju, kreditnu istoriju, menadžment, volatilnost cene i pokrivenost osiguranjem, konkurentsku prednost i diverzifikaciju kupaca.

Srednjim nivoom rizika identifikovana je barijera za ulazak, opasnost od substituta, kretitne prakse, uslova industrije, kursnog rizika i snabdevača.

Kao najveći rizik za preduzeće Laki komerc smatraju se tržišni uslovi, zbog osetljivosti na inflatorne i druge makroekonomske uticaje na koje samo preduzeće ne može da utiče, a mogu dovesti do valutnog i tržišnog rizika.

\section{ZAKLJUČAK}

Odobravanje kredita je složen proces koji se sprovodi $\mathrm{u}$ nekoliko sektora $\mathrm{u}$ banci. Tom prilikom se analiziraju finansijske performanse preduzeća koje aplicira za kredit, interni i eksterni faktori koji utiču na njegovo poslovanje, kao i izloženost rizicima. Finansijskoj analizi se daje veliki značaj u procesu odobravanja kredita, ali je potrebno napomenuti da ona nije dovoljna da bi se donela konačna odluka. Veoma je bitna pouzdanost podataka koji se nalaze u finansijskim izveštajima koji su dostupni kreditnim analitičarima $\mathrm{u}$ banci.
Rizike je teže predvideti, usled neizvesnosti njihovog nastajanja $\mathrm{u}$ budućnosti $\mathrm{i}$ zbog toga treba prikupiti $\mathrm{i}$ anlizirati brojne informacije o trenutnom, ali i poslovanju preduzeća $\mathrm{u}$ prethodnom periodu kako bi se mogla predvideti verovatnoća ispoljavanja nekog rizika u budućnosti i načini upravljanja rizicima.

Banka za svakog klijenta definiše iznos kredita koji mu može odobriti i uslove pod kojima se kredit plasira. Teškoće u vraćanju kredita od strane klijenta povećavaju izloženost banke kreditnom riziku.

\section{LITERATURA}

[1] Stevanović, N., Malinić, D., (2005). Upravljačko računovodstvo, Ekonomski fakultet u Beogradu

[2] Perović, V., Nerandžić, B., (2015). Poslovne finansije, Fakultet tehičkih nauka u Novom Sadu

[3] Nerandžić, B., Perović, V., (2013). Upravljačko računovodstvo - računovodstvo za menadžere, Fakultet tehičkih nauka u Novom Sadu

[4] Perović, V., Nerandžić, B., (2015). Poslovne finansije, Fakultet tehničkih nauka u Novom Sadu

[5] Nerandžić, B., Perović, V., (2013). Upravljačko računovodstvo-računovodstvo za menadžere, Fakultet tehničkih nauka u Novom Sadu

[6] Rodić, J., Andrić, M., Vukelić, G., Vukelić, B. (2015). Analiza finansijskih izveštaja, Ekonomika, Beograd

[7] Rodić, J., (1991).Teorija i analiza bilansa,Ekonomika Beograd

[8] Stevanović, N., Malinić, D., (2005). Upravljačko računovodstvo, Ekonomski fakultet u Beogradu

[9] Knežević, G., (2009). Analiza finansijskih izveštaja, Univerzitet Singidunum, Beograd

[10] Perović, V., Nerandžić, B., (2015). Poslovne finansije, Fakultet tehničkih nauka u Novom Sadu

[11] Nerandžić, B., Demko Rihter, J., (2017). Menadžersko računovodstvo - Praktikum, FTN Izdavaštvo, Novi Sad

\section{Kratka biografija:}

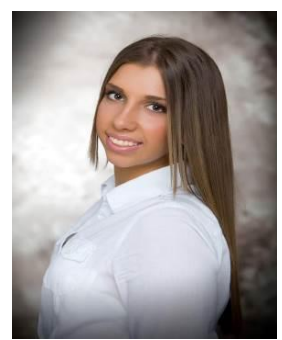

Milica Ničić rođena je 1996. godine u Novom Sadu. Diplomu o visokom obrazovanju je stekla na Fakultetu tehničkih nauka u Novom Sadu. Master rad na temu ,Analiza finansijskih performansi i izloženosti rizicima u funkciji donošenja odluke o kreditiranju', iz oblasti Inženjerskog menadžmenta obranila je na Fakultetu tehničkih nauka 2020. godine. 